\title{
Virulência de fungos entomopatogênicos a ninfas de Bemisia tabaci (Genn.) (Hemiptera: Aleyrodidae)
}

\section{Virulence of entomopathogenic fungi against nymphs of Bemisia tabaci (Genn.) (Hemiptera: Aleyrodidae)}

\author{
Michele Potrich ${ }^{*}$; Pedro Manuel Oliveira Janeiro Neves²; Luis Francisco Angeli \\ Alves $^{3}$; Mariana Pizzatto $;$ Everton Ricardi Lozano da Silva ${ }^{1}$; Daiane Luckmann ${ }^{4}$; \\ Alfredo de Gouvea ${ }^{1}$; Jéssica Cavalcanti Roman ${ }^{5}$
}

\begin{abstract}
Resumo
O objetivo deste trabalho foi avaliar a patogenicidade e a virulência dos isolados de Beauveria bassiana (Unioeste 47 e Unioeste 57), Metarhizium anisopliae (Unioeste 43 e Esalq 09) e Isaria sp. (IBCB 367 e

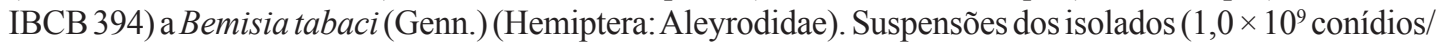
$\mathrm{mL}$ ) foram pulverizadas sobre ninfas de $3^{\circ}$ ínstar aderidas às folhas de couve. Para cada tratamento foram realizadas quatro repetições, com 20 insetos cada. A testemunha constou de água destilada esterilizada + Tween ${ }^{\circledR} 80(0,01 \%)$. Avaliou-se o número de ninfas mortas durante sete dias, que foram, posteriormente, mantidas em câmara úmida. Para a estimativa da concentração letal média $\left(\mathrm{CL}_{50}\right)$ as suspensões dos isolados $\left(1,0 \times 10^{5}, 1,0 \times 10^{6}, 1,0 \times 10^{7}, 1,0 \times 10^{8}\right.$ e $1,0 \times 10^{9}$ conídios $\left./ \mathrm{mL}\right)$ foram pulverizadas sobre ninfas de $3^{\circ}$ ínstar. Avaliou-se o número de ninfas com mortalidade confirmada pelo fungo. Os isolados B. bassiana Unioeste 47 (84,1\%) e Isaria sp. IBCB 367 (98,6\%) não diferiram significativamente entre si, provocando os maiores índices de mortalidade, enquanto o isolado M. anisopliae Esalq 09 provocou a menor mortalidade confirmada (23,2\%). A $\mathrm{CL}_{50}$ dos isolados de $B$. bassiana ficou entre $1,8 \times 10^{5} \mathrm{e} 4,1 \times$ $10^{5}$ conídios/mL (Unioeste 57 e Unioeste 47, respectivamente). Dentre os isolados de M. anisopliae, Esalq 09 apresentou maior $\mathrm{CL}_{50}\left(7,8 \times 10^{8}\right.$ conídios $\left./ \mathrm{mL}\right)$, enquanto Unioeste 43 esteve entre as menores $(4,3 \times$ $10^{5}$ conídios $/ \mathrm{mL}$ ). Os isolados de Isaria sp. apresentaram $\mathrm{CL}_{50}$ de $2,5 \times 10^{5}$ e $3,1 \times 10^{5}$ conídios $/ \mathrm{mL}$ (IBCB 367 e IBCB 394, respectivamente). Neste sentido, os isolados B. bassiana Unioeste 47 e Isaria sp. IBCB 367 apresentam potencial para controle de B. tabaci e para futuros trabalhos em campo.

Palavras-chave: Beauveria bassiana, Metarhizium anisopliae, Isaria sp., patogenicidade, controle biológico
\end{abstract}

\begin{abstract}
The objective of this study was to evaluate the pathogenicity and virulence of isolates of Beauveria bassiana (Unioeste 47 and Unioeste 57), Metarhizium anisopliae (Unioeste 43 and Esalq 09) and Isaria
\end{abstract}

\footnotetext{
1 Profs. Drs. da Coordenação de Ciências Biológicas. Universidade Tecnológica Federal do Paraná, Campus Dois Vizinhos, UTFPRDV. Estrada para Boa Esperança, Km 04, UTFPR, Comunidade São Cristóvao, CEP. 85660-000. Dois Vizinhos, PR. E-mail: michelepotrich@utfpr.edu.br; evertonlricardi@utfpr.edu.br; alfredo@utfpr.edu.br

2 Prof. Dr. do Dept ${ }^{\mathrm{o}}$ de Agronomia.Universidade Estadual de Londrina, UEL. Londrina, PR. Bolsista de Produtividade em Pesquisa, CNPq. E-mail: pedroneves@uel.br

3 Prof. Dr. Centro de Ciências Biológicas e da Saúde. Universidade Estadual do Oeste do Paraná, Campus Cascavel, UNIOESTE. Bolsista de Produtividade em Pesquisa, CNPq. E-mail: luis.alves@unioeste.br

4 Acadêmicas de Tecnologia em Horticultura. Universidade Tecnológica Federal do Paraná, Campus Dois Vizinhos, UTFPR-DV. E-mail: mariana_pizzatto@hotmail.com; daianeluck@yahoo.com.br

5 Acadêmica de Licenciatura em Ciências Biológicas. Universidade Estadual do Oeste do Paraná, Campus Cascavel, UNIOESTE. E-mail: jeh_cavalcanti@hotmail.com

* Autor para correspondência
}

Recebido para publicação 12/07/2010 Aprovado em 16/07/2011 
sp. (IBCB 367 and IBCB 394) against Bemisia tabaci (Genn.) (Hemiptera: Aleyrodidae). Suspensions of the isolates $\left(1.0 \times 10^{9}\right.$ conidia $\left./ \mathrm{mL}\right)$ were sprayed on third instar nymphs on cabbage leaves. It was performed four replications, each one with 20 insects, for each treatment. The control consisted of sterile distilled water + Tween $^{\circledR} 80(0.01 \%)$. The number of killed nymphs was evaluated during seven days, and then they were kept in a moist chamber. To estimate the median lethal concentration $\left(\mathrm{LC}_{50}\right)$, isolates suspensions of $1.0 \times 10^{5}, 1.0 \times 10^{6}, 1.0 \times 10^{7}, 1.0 \times 10^{8}$ and $1.0 \times 10^{9}$ conidia/mL were sprayed on third instar nymphs. The number of nymphs with confirmed mortality was evaluated. The isolates $B$. bassiana Unioeste 47 (84.1\%) and Isaria sp. IBCB 367 (98.6\%) did not differ significantly, causing the highest mortalities. However, the isolate M. anisopliae Esalq 09 caused the lower confirmed mortality (23.2\%). The $\mathrm{LC}_{50}$ of the $B$. bassiana isolates varied from $1.8 \times 10^{5}$ and $4.1 \times 10^{5}$ conidia $/ \mathrm{mL}$ (Unioeste 57 and Unioeste 47, respectively). Among the isolates of $M$. anisopliae, Esalq 09 presented the highest $\mathrm{LC}_{50}$ value $\left(7.8 \times 10^{8}\right.$ conidia $\left./ \mathrm{mL}\right)$, whereas Unioeste 43 presents the lowest $\left(4,3 \times 10^{5}\right.$ conidia $\left./ \mathrm{mL}\right)$. The Isaria sp. isolates presented $\mathrm{LC}_{50}$ of $2.5 \times 10^{5}$ and $3.1 \times 10^{5}$ conidia/mL (IBCB 367 and IBCB 394, respectively). Therefore, $B$. bassiana Unioeste 47 e Isaria sp. IBCB 367 isolates had potential to $B$. tabaci control and for future field studies.

Key words: Beauveria bassiana, Metarhizium anisopliae, Isaria sp., pathogenicity, biological control

\section{Introdução}

Bemisia tabaci(Genn.)(Hemiptera:Aleyrodidae) apresenta ampla distribuição geográfica, ocorrendo em diversas culturas (GALLO et al., 2002), tendo o biótipo $\mathrm{B}$ distribuição geográfica no estado do Paraná, mas associado à maior variedade de plantas hospedeiras (MARTINEZ et al., 2000). No tomateiro, B. tabaci reduz o vigor da planta, causa anomalias fisiológicas, favorece a ocorrência de fumagina, além de transmitir viroses (GALLO et al., 2002; FILGUEIRA, 2003), sendo que essas injúrias também estão associadas a outras culturas.

Para o controle de B. tabaci no tomateiro são recomendados inseticidas do grupo dos neonicotinóides, tiadiazinona, piretróides, éter piridiloxipropílico, benzoiluréia e feniltiouréia (PARANÁ-SEAB, 2010) e, como estratégia para o controle dessa praga em sistemas alternativos de produção de tomate há estudos com os fungos entomopatogênicos Beauveria bassiana (Bals.) Vuill., Isaria sp. (Wize) Brown \& Smith, Lecanicillium lecanii (Zimm.) Viégas e Metarhizium anisopliae (Metsch.) Sorok. (WRAIGHT et al., 1998; FARIA; WRAIGHT, 2001; VAZQUEZMORENO, 2002; RAMOS et al., 2004).
Segundo Faria e Wraight (2001), os fungos têm capacidade de suprimir e, muitas vezes, controlar B. tabaci, tanto em casa de vegetação quanto em campo. Desse modo, muitos trabalhos foram realizados com a finalidade de selecionar os isolados mais virulentos, de várias espécies de fungos entomopatogênicos para o controle desse inseto. Na seleção de isolados de $B$. bassiana para controle de Bemisia argentifolli ${ }^{5}$, Vicentini, Faria e Oliveira (2001) verificaram diferenças nas virulências dos isolados testados em ninfas. Em experimentos de laboratório, M. anisopliae provocou $89 \%$ de mortalidade em ninfas de $3^{\circ}$ ínstar de $B$. tabaci biótipo $\mathrm{B}$, sendo mais eficiente que os isolados de $B$. bassiana e de I. fumosorosea (RAMOS et al., 2004). O desenvolvimento de ninfas e adultos também pode ser comprometido pelos fungos entomopatogênicos, resultando em mal-formações nas fases subsequentes de desenvolvimento de B. tabaci quando estas foram pulverizadas com $I$. fumosorosea no $2^{\circ}$ ínstar (HUANG et al., 2010).

Nesse contexto, são necessários contínuos estudos de seleção de isolados de fungos entomopatogênicos, uma vez que estes apresentam grande variabilidade genética intra e inter-específicos.

5 Sinonímia de Bemisia tabaci biótipo B, sendo descrito Bemisia argentifolli conforme consta no manuscrito original, o mesmo procedimento foi adotado para as demais citações. 
Diante disso, o presente trabalho teve por objetivo comparar e avaliar a patogenicidade e a virulência de isolados dos fungos entomopatogênicos $B$. bassiana, M. anisopliae e Isaria sp. à mosca-branca B. tabaci, em condições de laboratório.

\section{Material e Métodos}

O cultivo de couve Brassica oleracea var. georgea foi realizado para criação da mosca-branca. Para tal, sementes de couve foram distribuídas em bandejas de isopor com 128 células, contendo substrato comercial Plantmax ${ }^{\circledR}$, sendo as bandejas mantidas em casa de vegetação por 30 dias, quando foram transplantadas para vasos plásticos com capacidade de 3,5 L.

A coleta e a criação de Bemisia tabaci foram realizadas da seguinte forma: ovos, ninfas e adultos de mosca-branca foram coletados em cultivo orgânico de tomate, no município de Marechal Cândido Rondon, PR. Para obtenção dos ovos, vasos contendo uma planta de couve foram deixados por 24 horas dentro de estufas de tomate, em contato com a parte mais alta das plantas, para que as moscas-brancas fizessem a oviposição. Para a obtenção das ninfas e adultos, foram coletadas partes da planta de tomate com a presença desse inseto. Os materiais coletados foram acondicionados em gaiolas $(40 \times 40 \times 60 \mathrm{~cm})$ contendo uma planta de couve (selecionada pelo seu desenvolvimento rápido e pela facilidade de criação de moscabranca), sendo mantidas em casa de vegetação "e", quando necessário, as plantas foram trocadas para a manutenção da população. Os exemplares desta espécie foram depositados na coleção entomológica da Universidade Tecnológica Federal do Paraná Câmpus Dois Vizinhos (UTFPR-DV) e enviados para identificação.

Para a multiplicação e preparação das suspensões dos isolados, utilizaram-se isolados das espécies B. bassiana, Isaria sp. e M. anisopliae, obtidos dos bancos de entomopatógenos do Laboratório de Controle Biológico/ Instituto Biológico de Campinas (IBCB), Laboratório de Controle Microbiano/ Escola Superior de Agricultura Luiz de Queiroz (ESALQ) e do Laboratório de Biotecnologia Agrícola/ Universidade Estadual do Oeste do Paraná (Unioeste) (Tabela 1).

Tabela 1. Isolados de fungos entomopatogênicos utilizados no bioensaio e respectiva origem.

\begin{tabular}{llll}
\hline Isolados & Espécie & Hospedeiro original ou substrato & Local de origem \\
\hline Unioeste 43 & M. anisopliae & Hymenoptera: Formicidae & São Miguel do Iguaçu/PR \\
Unioeste 47 & B. bassiana & Hemiptera: Pentatomidae & Primavera do Leste/MT \\
Unioeste 57 & B. bassiana & Hemiptera: Pentatomidae & Primavera do Leste/MT \\
IBCB 367 & Isaria sp. & Solo de pastagens & Cuiabá/MT \\
IBCB 394 & Isaria sp. & Solo de cana-de-açúcar & Espírito Sto. do Pinhal/SP \\
Esalq 09 & M. anisopliae & Mahanarva posticata & Pernambuco \\
\hline
\end{tabular}

Os isolados foram multiplicados em placas de Petri em meio de esporulação (M.E.) (ALVES et al., 1998) à temperatura de $26 \pm 1{ }^{\circ} \mathrm{C}$ e fotofase de 14 $\mathrm{h}$, por oito dias. Após oito dias, os conídios foram raspados do meio de cultura, com auxílio de uma espátula esterilizada, e armazenados em frascos esterilizados, em freezer, à temperatura de $-10 \pm$ $1{ }^{\circ} \mathrm{C}$. Os conídios foram suspensos em $10 \mathrm{~mL}$ de água destilada esterilizada $+\operatorname{Tween}^{\circledR} 80(0,01 \%)$ e agitados em vórtex por um minuto, sendo a suspensão quantificada em câmara de Neubauer, padronizada em $1,0 \times 10^{2}$ conídios/mL. Em seguida, $0,1 \mathrm{~mL}$ da 
suspensão foi espalhado com alça de Drigalski em placa de Petri contendo M.E. e, mantidas em câmara climatizada (26 $\pm 1{ }^{\circ} \mathrm{C}$; fotofase de $14 \mathrm{~h}$ ), por oito dias. Após a formação das colônias, uma foi repicada para outra placa, obtendo-se a cultura monospórica, com a multiplicação dos isolados monospóricos realizada conforme descrito anteriormente, sendo os conídios coletados, armazenados por um período não superior a 15 dias.

A partir destes, foram preparadas suspensões com água destilada esterilizada + Tween $^{\circledR} 80$ (0,01\%), agitadas por um minuto em Vórtex e quantificadas em câmara de Neubauer, padronizadas em 1,0 × $10^{9}$ conídios $/ \mathrm{mL}$.

Para a avaliação da patogenicidade de isolados para controle de $B$. tabaci procedeu-se da seguinte maneira: para a obtenção de ninfas de mesmo ínstar, foram selecionadas mudas de couve com folhas de aproximadamente $15 \mathrm{~cm}$ de comprimento. Em cada folha foram confinados 60 indivíduos adultos de $B$. tabaci e, estas foram isoladas utilizando-se sacos, confeccionados com tecido voil de $12 \times 20 \mathrm{~cm}$, presos ao pecíolo das folhas por um arame. Após $24 \mathrm{~h}$, os adultos foram retirados e após 15 dias as folhas foram destacadas da planta e as ninfas de $3^{\circ}$ ínstar foram utilizadas para os bioensaios por serem imóveis, permitindo a manipulação das mesmas (JAMES; BUCKNER; FREEMAN, 2003).

As ninfas aderidas às folhas de couve foram selecionadas com o auxílio de microscópio estereoscópico e, realizadas marcações ao lado de cada uma (JAMES; JARONSKI, 2000; VICENTINI; FARIA; OLIVEIRA, 2001).

As suspensões dos fungos na concentração de $1,0 \times 10^{9}$ conídios/mL (aproximadamente 5,0 $\times 10^{6}$ conídios $/ \mathrm{cm}^{2}$ ou $5,0 \times 10^{4}$ conídios $/ \mathrm{mm}^{2}$ ) foram pulverizadas, com auxílio de um aerógrafo Pneumatic Sagyma ${ }^{\circledR}$ acoplado a uma bomba Fanem $^{\circledR}$ de pressão constante $1,2 \mathrm{kgf} / \mathrm{cm}$, sobre as ninfas aderidas às folhas de couve. Posteriormente, os pecíolos das folhas de couve foram imersos em ágar-água $(1,5 \%)$ no interior de recipientes plásticos $(15 \times 20 \times 10 \mathrm{~cm}, \mathrm{C} \times \mathrm{L} \times \mathrm{A})$, para que as folhas se mantivessem túrgidas, (metodologia adaptada de WRAIGHT et al., 2000), sendo esses recipientes revestidos com capa de voil, para evitar a fuga de adultos, considerando que a pulverização foi realizada sobre o $3^{\circ}$ ínstar e que após sete dias os indivíduos pudessem atingir a fase adulta. Para cada tratamento foram realizadas quatro repetições, cada uma contendo 20 insetos. Na testemunha, as plantas foram pulverizadas somente com água destilada esterilizada + Tween $^{\circledR} 80(0,01 \%)$. Após o procedimento, os recipientes foram acondicionados em câmara climatizada a $26 \pm 1{ }^{\circ} \mathrm{C}$, fotofase de 14 h e U.R. de $70 \pm 10 \%$, conforme Vidal, Fargues e Lacey (1997).

Diariamente, avaliou-se o número de ninfas mortas, caracterizadas inicialmente por tegumento flácido e coloração leitosa, até o sétimo dia (LANDA et al., 1994; JAMES; JARONSKI, 2000). Para confirmar a mortalidade provocada pelo fungo, os insetos mortos, fixos nas folhas de couve, foram mantidos nos recipientes plásticos contendo ágar-água, vedados e acondicionados em câmara climatizada ( $26 \pm 1{ }^{\circ} \mathrm{C}$, fotofase de 14 h e U.R. de $70 \pm 10 \%$ ). Em alguns tratamentos, antes de montar a câmara úmida, as ninfas já apresentavam hifas emergidas em aberturas naturais. O delineamento experimental foi inteiramente casualizado e os dados foram submetidos à análise de variância (teste F), sendo as médias comparadas entre si pelo teste de Tukey, a 5\% de probabilidade, com auxílio do programa estatístico BioEstat ${ }^{\circledR} 5.0$ (AYRES et al., 2007).

\section{Estimativa da Concentração Letal Média $\left(C L_{50}\right)$}

Os isolados foram multiplicados conforme metodologia já descrita, e foram preparadas suspensões de conídios nas concentrações de 1,0 $\times 10^{5}, 1,0 \times 10^{6}, 1,0 \times 10^{7}, 1,0 \times 10^{8}$ e $1,0 \times 10^{9}$ conídios/mL (metodologia adaptada de QUESADAMORAGA et al., 2006), conforme procedimento descrito anteriormente. A mortalidade foi avaliada 
ao $7^{\circ}$ dia, considerando as ninfas com tegumento flácido e coloração leitosa. Para confirmação da mortalidade provocada pelo fungo, estas ninfas, fixas nas folhas de couve, foram mantidas nos recipientes plásticos contendo ágar-água, vedados e acondicionados em câmara climatizada $\left(26 \pm 1{ }^{\circ} \mathrm{C}\right.$, fotofase de 14 h e U.R. de $70 \pm 10 \%$ ). Em alguns tratamentos, no momento da avaliação, as ninfas já apresentavam hifas emergidas em aberturas naturais. A fim de estimar a $\mathrm{CL}_{50}$, os dados obtidos foram submetidos aos testes de normalidade de Shapiro-Wilk e de homogeneidade de Bartlett, sendo posteriormente ajustados ao modelo Binomial com função de ligação Probit. Os dados não ajustados ao modelo Probit foram ajustados ao modelo Logaritmo de regressão com auxílio do programa estatístico $\mathrm{R}^{\circledR}$ (R DEVELOPMENT CORE TEAM, 2008).

\section{Resultados e Discussão}

Os isolados Isaria sp. IBCB $367(98,6 \%)$ e B. bassiana Unioeste $47(84,1 \%)$ não diferiram significativamente entre si, provocando os maiores índices de mortalidade confirmada. No entanto, o isolado $M$. anisopliae Esalq 09 provocou a menor mortalidade $(23,2 \%)$ (Tabela 2$)$.

Tabela 2. Mortalidade confirmada (\%) ( \pm EP) de Bemisia tabaci pulverizadas com fungos entomopatogênicos. Temp. $26 \pm 2^{\circ} \mathrm{C}, 14 \mathrm{~h}$ de fotofase e U.R. $70 \pm 10 \%$.

\begin{tabular}{lcc}
\hline Tratamentos & Mortalidade Confirmada \\
\hline B. bassiana Unioeste 47 & $84,1 \pm 2,39$ ab \\
B. bassiana Unioeste 57 & $76,8 \pm 7,91 \quad$ bc \\
M. anisopliae Unioeste 43 & $71,0 \pm 3,54$ & bc \\
M. anisopliae Esalq 09 & $23,2 \pm 9,44 \quad \mathrm{~d}$ \\
Isaria sp. IBCB 367 & $98,6 \pm 1,25$ & a \\
Isaria sp. IBCB 394 & $65,2 \pm 6,77 \quad \mathrm{c}$ \\
\hline$p$ & 0,001 &
\end{tabular}

Médias seguidas pela mesma letra não diferem entre si pelo teste de Tukey $(\mathrm{p}<0,05)$.
Os resultados obtidos, utilizando-se ninfas de $3^{\circ}$ ínstar e aplicando-se o isolado B. bassiana Unioeste 47 (aproximadamente 5,0 × $10^{4}$ conídios/ $\mathrm{mm}^{2}$ ), se assemelham aos verificados por Wraight et al. (2000), em que isolados de B. bassiana (0,6$1,4 \times 10^{3}$ conídios $/ \mathrm{mm}^{2}$ ) apresentaram potencial de controle de $90 \%$ sobre ninfas de $3^{\circ}$ e $4^{\circ}$ ínstares de $B$. argentifolli, sete dias após a aplicação. No entanto, os isolados de $B$. bassiana $\left(1,2 \times 10^{4}\right.$ conídios $\left./ \mathrm{cm}^{2}\right)$, provocaram apenas $25,7 \%$ de mortalidade em ninfas de $1^{\circ}$ ínstar, nessa mesma espécie (VICENTINI; FARIA; OLIVEIRA, 2001), neste caso, podendo estar relacionado à baixa concentração de conídios por área, quando comparado aos outros trabalhos.

É importante ressaltar que resultados semelhantes foram observados em trabalhos que avaliaram conídios $/ \mathrm{mL}$, apresentando variações na porcentagem de mortalidade que podem estar relacionadas às diferentes concentrações de conídios avaliadas. Neste estudo, os isolados de B. bassiana $\left(1,0 \times 10^{9}\right.$ conídios $/ \mathrm{mL}$ ) provocaram 76,8 (Unioeste 57 ) e $84,1 \%$ (Unioeste 47 ) de mortalidade em ninfas de $3^{\circ}$ ínstar de B. taci. Já Saito e Sugiyama (2005) observaram que $B$. bassiana $\left(6,0 \times 10^{8}\right.$ conídios/ $\mathrm{mL}$ ), cinco dias após a aplicação, provocou $60 \%$ de mortalidade nas ninfas de $3^{\circ}$ ínstar de $B$. argentifolli. Contudo, ninfas desse mesmo ínstar apresentaram variações de 2 a $70 \%$ na mortalidade provocada por isolados de B. bassiana $\left(1,0 \times 10^{7}\right.$ conídios/ $\mathrm{mL}$ ) (RAMOS et al., 2004). Ainda em estudos semelhantes com $B$. bassiana $\left(1,0 \times 10^{8}\right.$ conídios/ $\mathrm{mL}$ ) sobre ninfas de $1^{\circ}$ ínstar de $B$. tabaci resultaram em 71,5\% de mortalidade (RAMOS et al., 2000).

Observou-se que as ninfas de B. tabaci infectadas por $B$. bassiana apresentaram coloração rosaavermelhada, relacionada à presença de oosporina, substância que inibe a colonização do inseto por outro micro-organismo, sendo este aspecto também verificado por Wraight et al. (1998) e Ramos et al. (2004).

No presente trabalho, o isolado $M$. anisopliae Esalq 09 , na concentração de 1,0 $\times 10^{9}$ conídios $/ \mathrm{mL}$, 
provocou a menor mortalidade confirmada $(23,2 \%)$. No entanto, este isolado, na concentração de $1,0 \times$ $10^{7}$ conídios/mL provocou mortalidade de $89 \%$ das ninfas de $3^{\circ}$ ínstar de $B$. tabaci biótipo B (RAMOS et al., 2004). Esta diferença pode estar relacionada à resistência das populações de $B$. tabaci utilizadas em cada bioensaio, pois neste estudo foram usados indivíduos da $1^{\mathrm{a}}$ geração de selvagens, mantidos em plantas de couve e, no segundo caso, indivíduos oriundos de criação em laboratório, mantidos em plantas de soja. De acordo com Poprawski e Jones (2000), tais fatores podem influenciar na suscetibilidade do inseto.

O isolado IBCB 367 de Isaria sp. causou 98,6\% de mortalidade em ninfas de $3^{\circ}$ ínstar e Isaria sp. IBCB 394, 65,2\% de mortalidade. Em trabalho semelhante foi verificado que I. fumosorosea $(6,0$ $\times 10^{8}$ conídios $/ \mathrm{mL}$ ) causou $98 \%$ de mortalidade em ninfas de $3^{\circ}$ ínstar de $B$. argentifolli (SAITO; SUGIYAMA, 2005). Conídios de I. fumosorosea apresentaram germinação significativa sobre $B$. argentifolli, oito horas após a aplicação, chegando a 99\% de germinação após 24 h (LANDA et al., 1994; VEGA; JACKSON; McGUIRE, 1999).

As espécies de fungos entomopatogênicos que provocaram os maiores índices de mortalidade confirmada observados neste estudo foram Isaria sp. e B. bassiana, corroborando Wraight et al. (2000). I. fumosorosea tem como vantagem a germinação rápida sobre ninfas de $B$. argentifolli, quando comparada a outras espécies de fungos (LANDA et al., 1994), sendo essa habilidade de germinação também verificada por Vega, Jackson e McGuire (1999). Os isolados que germinam mais rápido, apresentam maior potencial para infectar estágios imaturos, evitando o risco de eliminação durante a ecdise.

É importante salientar que a cutícula de $B$. argentifolli possui uma espessa camada de lipídios de cadeia longa e ésteres de cera que podem tanto facilitar a adesão dos conídios, como podem ter efeito tóxico ou inibidor sobre estes, atuando como primeira linha de defesa contra os fungos (BUCKNER; HAGEN; NELSON, 1999 apud JAMES; BUCKNER; FREEMAN, 2003).

Comparando a virulência de isolados de $B$. bassiana e $I$. fumosorosea sobre ninfas de $B$. argentifolli, Saito e Sugiyama (2005) verificaram que os isolados de I. fumosorosea foram os mais virulentos. O mesmo pode ser observado no presente trabalho, sugerindo que o efeito tóxico, inibidor ou fungistático possa ter ocorrido somente, ou em maior proporção, sobre o isolado $M$. anisopliae Esalq 09. As diferenças observadas também podem estar relacionadas ao muco produzido por alguns isolados, que apresentam propriedades antidessecantes e protegem os conídios dos efeitos tóxicos dos polifenóis presentes no hospedeiro (LEGER, 1993).

A espécie I. fumosorosea, após adesão, consegue utilizar os lipídios da cutícula como fonte de nutrientes (JAMES; BUCKNER; FREEMAN, 2003). Esse evento é possível devido à produção de lipases e estereases pelo fungo para a degradação e penetração na cutícula.

Pelos testes de normalidade de Shapiro Wilk e de homogeneidade de variância de Bartlett, os isolados Unioeste 57, Unioeste 43, Esalq 09 e IBCB 394 apresentaram distribuição normal e homogeneidade. No entanto, Unioeste 47 e IBCB 367 não foram significativos para estes testes. Também foi realizada a estimativa dos parâmetros do modelo, considerando o modelo Binomial com função de ligação Probit, através da estimativa da Deviance (função desvio), verificando que todos se apresentaram ajustados ao modelo $n_{i}=\beta+\alpha_{i}$, porém, o único isolado a se ajustar no modelo Probit e ser significativo foi Isaria sp. IBCB 367. Assim realizou-se a estimativa dos parâmetros pelo coeficiente de regressão, com modelo logaritmo: proporção $=\beta_{0}+\beta_{1} \times 1 \ln ($ dose $)$.

A estimativa da Concentração Letal Média $\left(\mathrm{CL}_{50}\right)$ com a utilização do modelo Probit, em testes envolvendo entomopatógenos, nem sempre 
é possível, pois os bioensaios não são do tipo estímulo-resposta, por isso, muitas vezes, os dados não se enquadram no modelo, devendo ser utilizado outro modelo (HADDAD, 1998), conforme verificado no presente trabalho.

A Concentração letal média $\left(\mathrm{CL}_{50}\right)$ dos isolados de $B$. bassiana ficou em $1,8 \times 10^{5}$ e 4,1 $\times 10^{5}$ conídios/mL para Unioeste 57 e Unioeste 47, respectivamente. Dentre os isolados de $M$. anisopliae, o isolado Esalq 09 apresentou a maior $\mathrm{CL}_{50}, 7,8 \times 10^{8}$ conídios/mL, o que identifica o isolado como pouco virulento, enquanto o isolado Unioeste 43 apresentou $4,3 \times 10^{5}$ conídios $/ \mathrm{mL}$. Os isolados de Isaria sp. apresentaram $\mathrm{CL}_{50}$ baixa, ficando em $3,1 \times 10^{5}$ conídios $/ \mathrm{mL}$ para IBCB 394 e $2,5 \times 10^{5}$ conídios $/ \mathrm{mL}$ para IBCB 367 (Tabela 3). Valores de $\mathrm{CL}_{50}$ semelhantes aos obtidos no presente trabalho foram verificados para isolados de $B$. bassiana sobre ninfas de $4^{\circ}$ ínstar de B. tabaci, que apresentaram $\mathrm{CL}_{50}$ baixa, $6,53 \times 10^{5}$ conídios/mL (QUESADA-MORAGA et al., 2006).

Tabela 3. Concentração Letal média $\left(\mathrm{CL}_{50}\right)$ de isolados de fungos entomopatogênicos a Bemisia tabaci avaliados no $7^{\circ}$ dia após a aplicação. Temp. $26 \pm 2{ }^{\circ} \mathrm{C}$, e 14 horas de fotofase e U.R. $70 \pm 10 \%$.

\begin{tabular}{|c|c|c|c|c|}
\hline Tratamentos & ${ }^{\beta 0}$ (p valor) & ${ }^{\beta 1}$ (p valor) & $\mathbf{R}^{2}$ & $\mathrm{CL}_{50}(\mathrm{IC} 95 \%)$ \\
\hline \multicolumn{5}{|l|}{ B. bassiana } \\
\hline Unioeste 47 & $-0,3487\left(1,0 \times 10^{-2}\right)^{*}$ & $0,0657\left(1,0 \times 10^{-3}\right)^{*}$ & 0,613 & $\begin{array}{c}4,1 \times 10^{5} \\
\left(1,8 \times 10^{5}-6,4 \times 10^{5}\right)\end{array}$ \\
\hline \multicolumn{5}{|l|}{ B. bassiana } \\
\hline Unioeste 57 & $-0,6037\left(4,3 \times 10^{-4}\right)^{*}$ & $0,0765\left(4,8 \times 10^{-8}\right)^{*}$ & 0,816 & $\begin{array}{c}1,8 \times 10^{5} \\
\left(3,3 \times 10^{4}-2,6 \times 10^{5}\right)\end{array}$ \\
\hline \multicolumn{5}{|l|}{ M. anisopliae } \\
\hline Unioeste 43 & $-0,6775\left(7,9 \times 10^{-6}\right)^{*}$ & $0,0304\left(9,4 \times 10^{-10}\right)^{*}$ & 0,881 & $\begin{array}{c}4,3 \times 10^{5} \\
\left(3,3 \times 10^{5}-5,3 \times 10^{5}\right)\end{array}$ \\
\hline \multicolumn{5}{|l|}{ M. anisopliae } \\
\hline Esalq 09 & $-0,1925\left(1,4 \times 10^{-1}\right)^{*}$ & $0,0304\left(7,0 \times 10^{-4}\right)^{*}$ & 0,475 & $\begin{array}{c}7,8 \times 10^{8} \\
\left(5,4 \times 10^{8}-1,0 \times 10^{9}\right)\end{array}$ \\
\hline \multicolumn{5}{|l|}{ Isaria sp. } \\
\hline IBCB 367 & $-1,0287\left(1,7 \times 10^{-7}\right)^{*}$ & $0,1037\left(6,4 \times 10^{-11}\right)^{*}$ & 0,912 & $\begin{array}{c}2,5 \times 10^{5} \\
\left(1,5 \times 10^{5}-3,5 \times 10^{5}\right)\end{array}$ \\
\hline $\begin{array}{l}\text { Isaria } \mathrm{sp} . \\
\text { IBCB } 394\end{array}$ & $-0,5460\left(8,0 \times 10^{-3}\right)^{*}$ & $0,0700\left(5,7 \times 10^{-6}\right)^{*}$ & 0,690 & $\begin{array}{c}3,1 \times 10^{5} \\
\left(1,3 \times 10^{5}-4,9 \times 10^{5}\right)\end{array}$ \\
\hline
\end{tabular}

* $\mathrm{p}<0,05$ : estimativas são diferentes de zero. IC: Intervalo de Confiança.

A $\mathrm{CL}_{50}$ de Isaria sp. observada no presente trabalho é maior do que a $\mathrm{CL}_{50}$ de $I$. fumosorosea obtida por Saito e Sugiyama (2005), calculada em $1,1 \times 10^{4}$ conídios/mL para ninfas de $3^{\circ}$ ínstar de $B$. argentifolli, sendo considerado mais virulento. Porém, para ninfas de $2^{\circ}$ ínstar de $B$. tabaci, Huang et al. (2010) obtiveram $\mathrm{CL}_{50}$ de I. fumosorosea de
$2,16 \times 10^{6}$ conídios $/ \mathrm{mL}$.

A alta virulência a $B$. argentifolli foi associada às espécies I. fumosorosea e B. bassiana (WRAIGHT et al., 1998), sendo o mesmo observado no presente trabalho. A virulência de $B$. bassiana, $M$. anisopliae e Isaria sp. é, frequentemente, relacionada à rápida 
germinação de conídios sobre o hospedeiro e aos índices de crescimento do entomopatógeno (LEGER, 1993).

A proteína Mad1 e as dextruxinas, toxinas de M. anisopliae, são determinantes da virulência desse entomopatógeno (KERSHAW et al., 1999; WANG; LEGER, 2007). Sendo assim, os isolados mais virulentos, poderiam apresentar a dextruxina na sua composição. No entanto, segundo Leger (1993), nenhum componente sozinho, ou ação, pode ser considerado o determinante da virulência de um isolado.

Assim, os isolados B. bassiana Unioeste $47 \mathrm{e}$ Isaria sp. IBCB 367 apresentam potencial para serem utilizados em programas de controle de $B$. tabaci, uma vez que foram patogênicos a esse inseto e apresentaram baixos valores de CL50. Já o isolado M. anisopliae Esalq 09 não é recomendado, pois apresentou baixo índice de mortalidade confirmada, além de elevada $\mathrm{CL}_{50}$.

\section{Referências}

ALVES, S. B.; ALMEIDA, J. E. M.; MOINO JÚNIOR, A.; ALVES, L. F. A. Técnicas de laboratório. In: ALVES, S. B. (Ed.). Controle microbiano de insetos. 2. ed. Piracicaba: FEALQ, 1998, 1163 p.

AYRES, M.; AYRES JUNIOR, M.; AYRES, D. L.; SANTOS, A. A. S. BioEstat 5.0. Aplicações estatísticas nas áreas de Ciências Bio-Médicas. Belém: Sociedade Civil Mamirauá; Brasília CNPq, 2007. 324 p.

FARIA, M.; WRAIGHT, S. P. Biological control of Bemisia tabaci with fungi. Crop Protection, Pullman, v. 20, n. 9, p. 767-778, 2001.

FILGUEIRA, F. A. R. Novo manual e olericultura: agrotecnologia moderna na produção e comercialização de hortaliças. 2. ed. Viçosa: UFV, 2003. 412 p.

GALLO, D.; NAKANO, O.; SILVEIRA NETO, S.; CARVALHO, R. P. L.; BAPTISTA, G. C.; BERTI FILHO, E.; PARRA, J. R. P.; ZUCCHI, R. A.; ALVES, S. B.; VENDRAMIM, J. D.; MARCHINI, L. C.; LOPES, J. R. S.; OMOTO, C. Entomologia agrícola. Piracicaba: FEALQ, 2002. v. 10, 920 p.

HADDAD, M. L. Utilização do polo-PC para análise de probit. In: ALVES, S. B. (Ed.). Controle microbiano de insetos. 2. ed. Piracicaba: FEALQ, 1998, 1163 p.

HUANG, Z.; ALI, S.; REN, S. H.; WU, J. H. Effect of Isaria fumosoroseus on mortality and fecundity of Bemisia tabaci and Plutella xylostella. Insect Science, China, v. 17, n. 2, p. 140-148, 2010.

JAMES, R. R.; BUCKNER, J. S.; FREEMANC, T. P. Cuticular lipids and silverleaf whitefly stage effect conidial germination of Beauveria bassiana and Paecilomyces fumosoroseus. Journal of Invertebrate Pathology, Riverside, v. 84, n. 2, p. 67-74, 2003.

JAMES, R .R.; JARONSKI, S. T. Effect of low viability on infectivity of Beauveria bassiana conidia toward the silverleaf whitefly. Journal of Invertebrate Pathology, Riverside, v. 76, n. 3, p. 227-228, 2000.

KERSHAW, M. J.; MOORHOUSE, E. R.; BATEMAN, R.; REYNOLDS, S. E.; CHARNLEY, A. K. The role of destruxins in the pathogenicity of Metarhizium anisopliae for three species of insect. Journal of Invertebrate Pathology, Riverside, v. 74, n. 3, p. 213-223, 1999.

LANDA, Z.; OSBORNE, L.; LOPEZ, F.; EYAL, J. A bioassay for determining pathogenicity of entomogenous fungi on whiteflies. Biological Control, Orlando, v. 4, n. 4, p. 341-350, 1994.

LEGER, R. J. S. Biology and mechanisms of insectcuticle invasion by deuteromycete fungal pathogens. In.: THOMPSON; S. N.; FERERICI, B. A. Parasites and pathogens of insects. London: Pathogens Acad. Press, 1993. v. 2, p. 211-227.

MARTINEZ, S. S.; CARVALHO, A. O. R.; VIEIRA, L. G.; NUNES, L. M.; BIANCHINI, A. Identification, Geographical Distribution and Host Plants of Bemisia tabaci (Genn.) Biotypes (Homoptera: Aleyrodidae) in the State of Paraná, Brazil. An. Soc. Entomol. Brasil., Londrina, v. 29, n. 3, p. 597-603, 2000.

PARANÁ. Secretaria de Agricultura e Abastecimento do Paraná - SEAB. Lista de agrotóxicos aptos para comércio e uso no Paraná. 2010. Disponível em: <http:/ www.seab.pr.gov.br/arquivos/File/defis/DFI/Lista.pdf $>$. Acesso em: 21 maio 2010.

POPRAWSKI, T. J.; JONES, W. J. Host plant effects on activity of the mitosporic fungi Beauveria bassiana and Paecilomyces fumosoroseus against two populations of Bemisia whiteflies (Homoptera: Aleyrodidae). Mycopathologia, Den Haag, v. 151, n. 1, p. 11-20, 2000.

QUESADA-MORAGA, E.; MARANHAO, E. A. A.; VALVERDE-GARCÍA, P.; SANTIAGO-ÁLVAREZ, C. Selection of Beauveria bassiana isolates for control of the whiteflies Bemisia tabaci and Trialeurodes vaporariorum on the basis of their virulence, thermal requirements, and 
toxicogenic activity. Biological Control, Orlando, v. 36, n. 3, p. 274-287, 2006.

RAMOS, E. Q.; ALVES, S. B.; DEMÉTRIO, C .G. B.; COSTA, S .C. Seleção de fungos entomopatogênicos para o controle de Bemisia tabaci biótipo B. Manejo Integrado de Plagas y Agroecologia, Costa Rica, n. 73, p. 21-28, 2004.

RAMOS, E. Q.; ALVES, S. B.; TANZINI, M. R.; LOPES, R. B. Susceptibilidad de Bemisia tabaci a Beauveria bassiana em condiciones de laboratório. Manejo Integrado de Plagas, Costa Rica, n. 56, p. 65-69, 2000.

R DEVELOPMENT CORE TEAM. R. A language and environment for statistical computing. R Foundation for Statistical. Computing, Vienna, Austria. 2008.

SAITO, T.; SUGIYAMA, K. Pathogenicity of three Japanese strains of entomopathogenic fungi against the silverleaf whitefly, Bemisia argentifolii. Appl. Entomol. Zool., Japão, v. 40, n. 1, p. 169-172, 2005.

VAZQUEZ-MORENO, L. L. Advances in the biological control of the whitefly Bemisia tabaci in the Neotropical region. Manejo Integrado de Plagas y Agroecologia, Costa Rica, n. 66, p. 82-95, 2002.

VEGA, F. A.; JACKSON, M. A.; McGUIRE, M. R. Germination of conidia and blastospores of Paecilomyces fumosoroseus on the cuticle of the silverleaf whitefly, Bemisia argentifolii. Mycopathologia, Dan Haag, v. 147, n. 1, p. 33-35, 1999.

VICENTINI, S.; FARIA, M.; OLIVEIRA, M. R. V. Screening of Beauveria bassiana (Deuteromycotina: Hyphomycetes) Isolates Against Nymphs of Bemisia tabaci (Genn.) Biotype B (Hemiptera: Aleyrodidae) with Description of a New Bioassay Method. Neotropical Entomology, Londrina, v. 30, n. 1, p. 97-103, 2001.

VIDAL, C.; FARGUES, J.; LACEY, L. A. Intraspecific variability of Paecilomyces fumosoroseus: effect of temperature on vegetative growth. Journal of Invertebrate Pathology, Riverside, v. 70, n. 1, p. 18-26, 1997.

WANG, C.; St. LEGER, R. J. The MAD1 Adhesin of Metarhizium anisopliae links adhesion with blastospore production and virulence to insects, and the MAD2 adhesin enables attachment to plants. Eukaryotic Cell., Washington, v. 6, n. 5, p. 808-816, may, 2007.

WRAIGHT, S. P.; CARRUTHERS, R. I.; BRADLEY, C. A.; JARONSKI, S. T.; LACEY, L. A.; WOOD, P.; GALAINI-WRAIGHT, S. Pathogenicity of the entomopathogenic fungi Paecilomyces spp. and Beauveria bassiana against the silverleaf whitefly, Bemisia argentifolii. Journal of Invertebrate Pathology,
Riverside, v. 71, n. 3, p. 217-226, 1998.

WRAIGHT, S. P.; CARRUTHERS, R. I.; JARONSKI, S. T.; BRADLEY, C. A.; GARZA, C. J.; GALAINIWRAIGHT, S. Evaluation of the entomopathogenic fungi Beauveria bassiana and Paecilomyces fumosoroseus for microbial control of the silverleaf whitefly, Bemisia argentifolii. Biological Control, Orlando, v. 17, n. 3, p. 203-217, 2000. 
